\title{
Proksimal tibia ve tibia diyafiz kırıkları
}

\author{
Tibia proximal and diaphyseal fractures
}

\author{
Burkay Çamurdan, Tolgahan Korkmaz, Ali Şeker
}

İstanbul Üniversitesi-Cerrahpaşa, Cerrahpaşa Tıp Fakültesi, Ortopedi ve Travmatoloji Anabilim Dalı, İstanbul

Tibia ve fibula kırıkları, önkol ve femur kırıklarından sonra çocuklarda görülen en sık üçüncü pediatrik uzun kemik kırıklarıdır. Proksimal tibial bölge yaralanmaları sık olmamakla birlikte, gençlerin ve çocukların son yıllarda spor faaliyetlerine katılımının artmasıyla birlikte sıklığı artmaktadır. Büyüme kıkırdağının bu bölgede yer alması, nörovasküler yapıların yakın komşuluğu nedeniyle proksimal tibia kırıkları özel önem arz eder. Tanı, ön-arka ve yan grafiler yardımıyla konulur. Şüpheli olgularda ileri görüntüleme yöntemleri (bilgisayarlı tomografi, manyetik rezonans görüntüleme) kullanılabilir. Tedavi kararında genellikle kırığın ayrışma miktarı belirleyicidir. Hangi tedavi kullanılırsa kullanılsın, büyüme kıkırdağının yerleşimi dolayısıyla ekstremite deformitesi ve dejeneratif eklem hastalığının gelişmemesi için uygun dizilimin elde edilmesi ve korunması tedavide esastır. Tibia ve fibula diyafiz kırıklarında oluş mekanizması, düşme, spor yaralanmaları veya trafik kazalarıdır. Kırık oluşum mekanizmasına göre klinik yansımalar değişkenlik göstermekte ve yaşa bağlı farklı tedavi şekilleri uygulanabilmektedir. Pediatrik tibia ve fibula kırıklarının büyük çoğunluğu konservatif yöntemlerle tedavi edilirken, büyük çocuklar ve kabul edilebilir sınırların dışında dizilimdeki kırıklarda, cerrahi tedavi yöntemleri ile tespit (Kirschner telleri, titanyum esnek çiviler, plak/vida, eksternal fiksatör) tercih edilebilir.

Anahtar sözcükler: tibia kırıkları; pediatri; proksimal; diyafiz
Tibial and fibular fractures are the third most common pediatric long bone injuries after forearm and femoral fractures. Proximal tibial injuries have an increasing frequency in recent years, parallel with the increasing sports activities of the children and adolescents. The clinical significance of proximal tibial fractures arises from the presence of the growth plate and the close proximity to the neurovascular structures. Anterior-posterior and lateral X-ray imaging is used for diagnosis. Advanced imaging methods (i.e., computed tomography, magnetic resonance imaging) can be used in suspected cases. The amount of displacement is usually decisive for the treatment method. Regardless of which treatment is used, the main objective is to achieve and maintain the appropriate alignment in order to prevent deformity and degenerative joint disease. The mechanisms of injury for tibial and fibular diaphyseal fractures are falls, sport injuries and traffic accidents. Clinical signs may differ depending on the fracture mechanism, and the treatment options are age-related. Majority of fractures can be treated with conservative modalities. In case of older children and/or unacceptable misalignments, surgical procedures (e.g., fixation with $\mathrm{K}$-wires, titanium elastic nails, plate/screws, external fixators) can be preferred.

Key words: tibia fracture; pediatrics; proximal; diaphyseal

\section{PROKSIMAL TIBIAA KIRIKLARI}

Proksimal tibial bölge yaralanmaları sık olmamakla birlikte, gençlerin ve çocukların son yıllarda spor faaliyetlerine katılımının artmasıyla birlikte sıklığı artan yaralanmalardandır. ${ }^{[1]}$ Büyüme kıkırdağının bu bölgede yer alması ve nörovasküler yapıların yakın komşuluğu nedeniyle proksimal tibia kırıkları özel önem arz eder. Tibial eminens, tibial tüberkül, tibial fizis ve metafiz kırıklarının oluşum mekanizması ve fizik muayene bulguları farklılık gösterir. Tanı, ön-arka ve yan grafiler yardımıyla konulur. Şüpheli olgularda ileri görüntüleme yöntemleri (bilgisayarlı tomografi [BT] ya da manyetik rezonans [MR] görüntüleme ) kullanılabilir. Tedavi kararında, genellikle kırığın ayrışma miktarı belirleyicidir. Hangi tedavi kullanılırsa kullanılsın, büyüme kıkırdağının yerleşimi dolayısıyla ekstremite deformitesi ve dejeneratif eklem hastalığının gelişmemesi için uygun dizilimin elde edilmesi ve korunması tedavide esastır. ${ }^{[1,2]}$

- İletişim adresi: Doç. Dr. Ali Şeker, İstanbul Üniversitesi-Cerrahpaşa, Cerrahpaşa Tıp Fakültesi Ortopedi ve Travmatoloji Anabilim Dalı, Kocamustafapaşa, Fatih, İstanbul Tel: 0532 - 3262202 e-posta: aliseker@doctor.com

- Geliș tarihi: 2 Subat $2019 \quad$ Kabul tarihi: 2 Subat 2019 
Diz, çocukluk çağında spor yaralanmalarında en sık etkilenen bölgelerdendir. Bu bölge yaralanmalarına yaklaşımda, bölge anatomisi ve fizyolojisinin iyi bilinmesi gerekir. Proksimal tibial kemikleşme çekirdeği doğumda mevcuttur. İkincil kemikleşme merkezi ise 9-14 yaşları arasında oluşur ve 15 yaş civarı proksimal tibial epifiz ile birleşir. Proksimal tibial fizis posteromediyalden anterolaterale doğru, önce merkez sonra perifer olacak şekilde matürasyonunu tamamlar. Büyüme kıkırdağının distaline uzanan bağlar, kuvvetleri daha distale transfer ederek büyüme kıkırdağının korunmasında rol oynar. Ayrıca, tibiofibular eklem de destek görevi görmektedir. ${ }^{[1]}$

\section{Epidemiyoloji}

Proksimal tibia kırıkları, tibia diyafiz ve tibia distal kırıklarına oranla daha nadir görülür. Genellikle indirekt kuvvetlerle meydana gelir ve fibula torus kırıkları gibi çevre dokuların yaralanmaları da sık eşlik eder. ${ }^{[1]}$ Özellikle 1-3 yaş arası çocuklarda metafiziyel köşe kırıkları çocuk istismarılya ilişkili olabilir. Üç ile dokuz yaş aralığındaki çocuklarda yeşil ağaç kırıkları ve komplet metafiziyel kırıklar, trombolin ve benzeri aletlerde zıplama sırasında oluşan valgus ve varus kuvvetleriyle oluşur. ${ }^{[2]}$ On ile on iki yaş aralığındaki çocuklar, hiperekstansiyon ve rotasyon hareketleriyle oluşan yaralanmalarda görülen tibial eminens kırıkları açısından risk altındadır. On üç yaş ve daha büyük çocuklarda, yüksek enerjili travma sonrası fizis kırığı riski artmıştır. Büyük çocuklarda daha sık görülen tibial tüberkül kırıkları, derin fleksiyon ardından ani kuadriseps kası kasılması sonucu, basketbol, yüksek atlama ve jimnastik gibi aktivitelerle oluşur. ${ }^{[1-4]}$

\section{Tibial Tüberkül Kırıkları}

Tibial tüberkül kırıkları, kuadriseps kasının güçlü ve ani kasılmasıyla birlikte dizin aktif ekstansiyonu ile ya da kasılmış kuadriseps kasına karşıt olarak dizin pasif fleksiyon hareketleri sonucu oluşur. Bu yaralanmalarda ilk mekanizma zıplama aktiviteleri, ikincisi ise futbol oyunu esnasında ikili mücadelelerde darbe ile birlikte olandır. Hastanın genellikle, spor aktivitesi sırasında başlayan diz ağrısı şikâyeti mevcuttur ve dizini tam ekstansiyona getiremediğinden yakınır. Fizik muayenede şişlik ve tibial tüberkül izdüşümünde hassasiyet mevcuttur. Diz $20-30^{\circ}$ fleksiyondadır. Ayrışmış kırıklarda tibial tüberkül seviyesinde deformite palpe edilebilir. Bu kırıklarda patella proksimale doğru yer değiştirebilir. Hasta aktif diz ekstansiyonu yapamaz ve pasif fleksiyonla ağrı hisseder. Muayenede, özellikle anteriorda olmak üzere, kompartmanların değerlendirilmesi ve nörovasküler muayene atlanmamalıdır; zira bu kırıklarda kompartman sendromu riski yüksektir. ${ }^{[4-7]}$
Tibia tüberkül kırıklarının Osgood-Schlatter hastalığı ile ilişkili olabileceğine dair yayınlar mevcuttur. Illk önceleri kullanılan Watson-Jones sınıflaması, Ogden tarafından geliştirilmiştir. Buna göre: Tip 1 kırık proksimal tibia kemikleşme merkezinin (birincil kemikleşme merkezi) distalindedir; Tip 2 kırık proksimal tibia kemikleşme merkezi ile tibial tüberkül arasındaki bileşkede (birincil ve ikincil kemikleşme merkezleri arasında) bulunur; Tip 3 kırık ekleme uzanır ve anteriora deplase olur; Tip 4 kırıklarda kırık hattı birincil kemikleşme merkezi boyunca uzanır. Tüm bu kırıklar kendi içinde tek parçalı $(A)$ ve çok parçalı (B) olmalarına göre alt tiplere ayrılır. Tip 5 kırıklarda ise patellar tendonun tüberküle yapışma bölgesinde sıyrılma olur (Şekil 1). ${ }^{[1,4-7]}$

Çocuklarda, özellikle yan grafı tanıda yardımcıdır. Küçük çocuklarda, diğer diz ile mukayeseli değerlendirme yararlı olabilir. Tibial tüberkülün ayrışması için patella seviyesi referans noktası olarak kullanılabilir ve Insall-Salvati tekniği ile ölçüm yapılabilir. Patellanın longitudinal uzunluğu ile patella alt polünün tibia tüberkülüne uzaklığı oranlanır; bu oran 0,8 ile 1,2 arasında olmalıdır. Oranın azalması, tibial tüberkül kırığı açısından uyarıcıdır. Cerrahi, bu kırıklarda başlıca tedavi iken; Ogden Tip 1 ve az ayrışmış kırıklarda diz tam ekstansiyonda uzun bacak alçılama yapılabilir. Alçının 6-8 hafta kalması önerilir. Alçı çıkarıldıktan sonra, hasta tolere edebildiği kadar yük verebilir. ${ }^{[2]}$ Ogden Tip 2, 3, 4 ve 5 kırıklarda kırık hematomu dekompresyonu, anatomik redüksiyon ve stabil internal tespit yapılmalıdır. Ayrıca Tip 3 kırıklarda eklem içi patolojiler açısından değerlendirme önerilir. Spongiyöz vidalar, Kirschner teli (K-teli), gergi bandı yöntemi kırık parçanın tespitinde tercih edilebilir. Profilaktik anterior kompartman fasyotomisi yapılabilir. Dört ila altı hafta uzun bacak alçı/breys tedavisinin ardından, 4-6 hafta da aktif ve pasif eklem hareket açıklığı ve kuadriseps kuvvet egzersizleri önerilir. ${ }^{[3-6]}$

Tibial tüberkül kırıklarında tedavi sonrası prognoz genellikle iyidir. Çocuk neredeyse yaralanma öncesindeki tüm aktivitelerine dönebilir; ancak kompartman sendromu, eklem sertliği, tibial tüberkülün belirginleşmesi görülebilmektedir. Genu rekurvatum, daha küçük çocuklarda anterior fiziyel arrest nedeniyle oluşabilir. Yaralanma çocukluk döneminin ileri yaşlarında olduğunda, özellikle Tip 3 kırıklarda meniskal patolojilerin araştırılması önerilir. Enfeksiyon, kaynamama, refraktür diğer nadir komplikasyonlardandır. ${ }^{[3-9]}$

\section{Tibial Eminens Kırıkları}

İnterkondiler eminens, tibia platosunda eklem yüzleri arasında bulunur. Ön çapraz bağ ile bağlantısı bulunan mediyal ve lateral eminens olarak adlandırılan iki parçadan oluşur. Bu iki yapı mediyal ve 

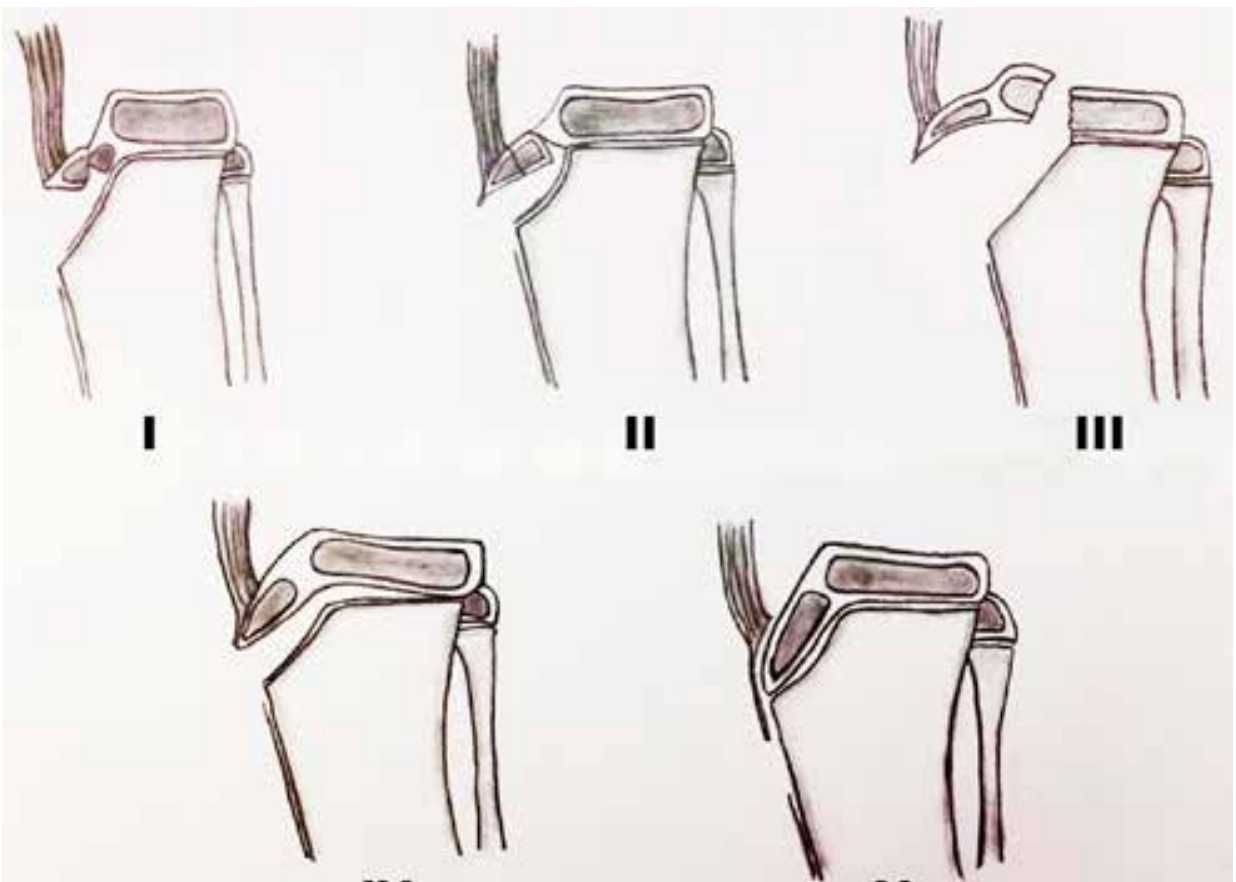

IV

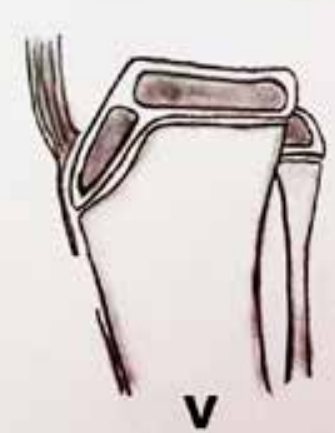

Şekil 1. Tibial tuberkül kırıkları için Ogden sınıflaması.

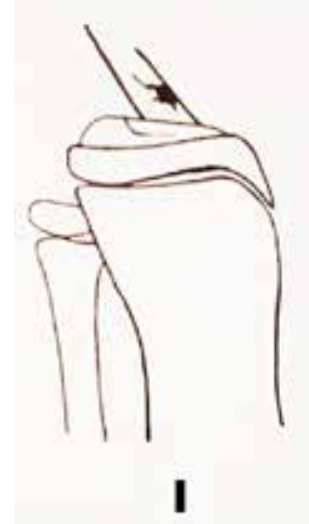

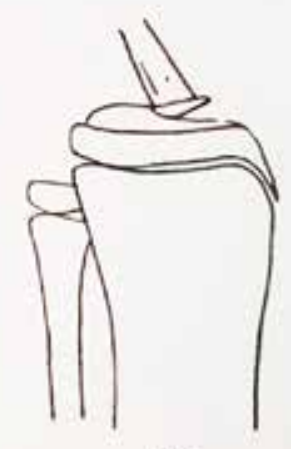

II

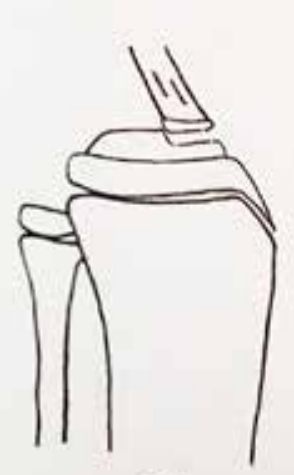

III

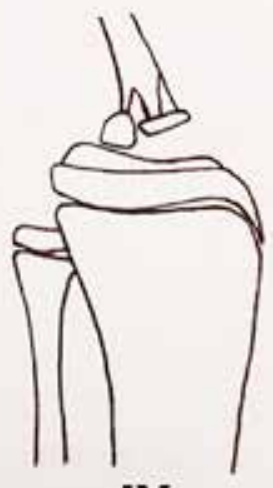

IV

Şekil 2. Tibial eminens kırıkları için Meyers \& McKeever sınıflaması.

lateral menisküslerin ön boynuzlarının kemik bağlantıları komşuluğundadır. Ön çapraz bağ lifleri intermeniskal bağ ve menisküs bağlantılarına karışarak sonlanır.

Tibial eminens kırıkları, çoğunlukla ekstansiyondaki dizin ani rotasyon hareketi sonucunda oluşur. Meyers ve McKeever, ayrışma miktarını temel alarak yan grafide tibial eminens avulsiyon kırıklarını sınıflamışlardır (Şekil 2). Tip 1 kırıkta, kırık parçası az ayrışmıştır. Tip 2 kırıkta, kırık parçası ayrışmış ancak posterior sınırı sağlamdır. Tip 3 kırıkta, kırık parçası tamamen ayrışmıştır. Tip 4 kırıkta, kopan parça rotasyonda durur. ${ }^{[1,3]}$
Fizik muayenede genellikle, kırık nedeni ile hemartroz mevcuttur. Diz fleksiyondadır ve aktif ekstansiyona getirilemez. Pasif ekstansiyon ile hasta ağrı duyar. Ağrı ve spazm nedeniyle diz stabilitesi değerlendirilemeyebilir, ancak varus ve valgus instabilitesinin değerlendirilme imkânı bulunabilir. Görüntülemede ön-arka ve yan grafi kullanılır; oblik grafi tanıyı desteklemek için kullanılabilir. Ayrışma izlenen kırıklarda ve şüpheli olgularda BT veya MR görüntüleme kullanılabilir.

Tip 1 kırıkların tedavisinde kapalı redüksiyon ve ekstansiyonda uzun bacak alçı tercih edilir. ${ }^{[3]}$ Tip 2 kırıklar 


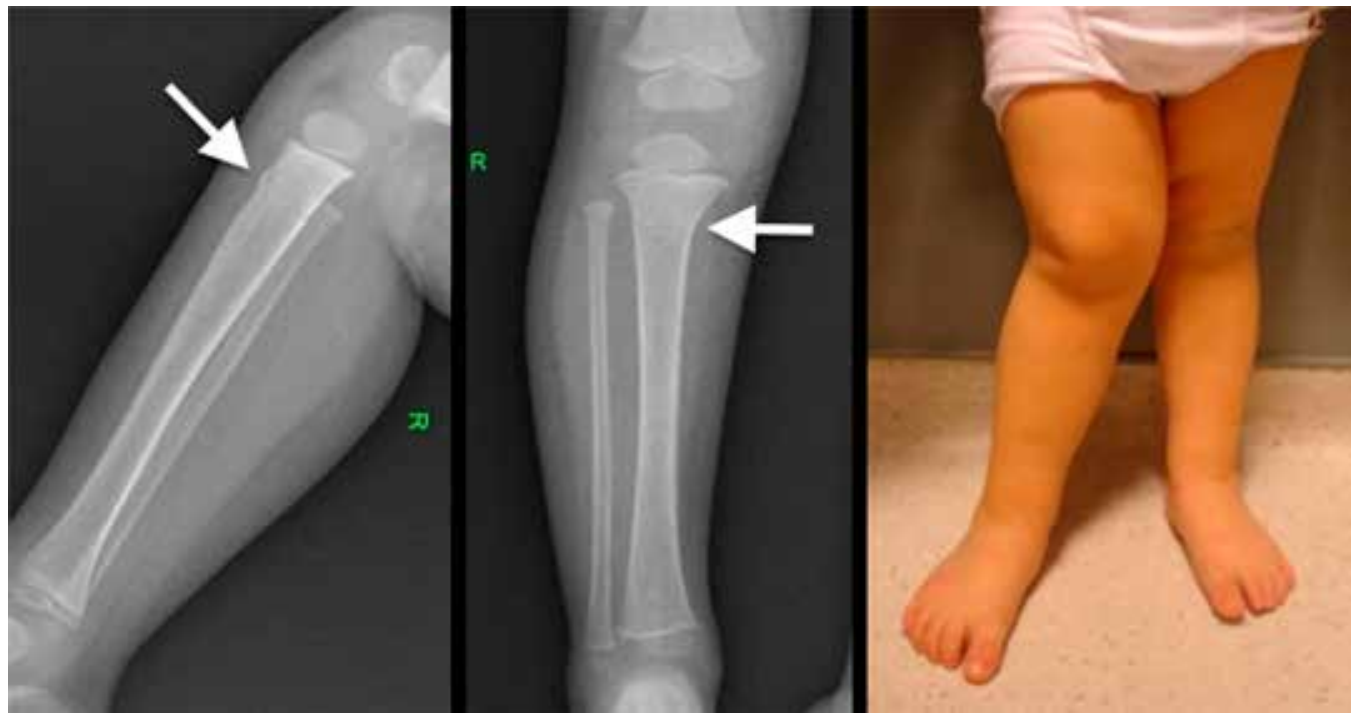

Şekil 3. Proksimal tibia metafiz kırı̆̆ı olan bir hastada gelişen Cozen fenomeni nedeniyle oluşan alt ekstremite valgus deformitesi.

gibi deplase kırıklarda da kapalı redüksiyon denenebilir. Başarılı olunamaz ise artroskopik veya açık redüksiyon uygulanmalıdır. Redüksiyonu intermeniskal bağın ve mediyal menisküsün ön boynuzunun kırık hattına girmiş olması, lateral menisküs ön boynuzunun kırık parçasını superolaterale çekmesi engelleyebilir. Kapalı redüksiyon, dizi şiş olan hastalarda hemartrozun aspirasyonu sonrası diz hiperfleksiyona alınıp, ardından yavaşça $0^{\circ}$ ye kadar ekstansiyona getirilerek yapılır. Takiben uzun bacak alçı uygulanmalıdır. Redüksiyonun sağlandığından emin olunduktan sonra, ayrışma ihtimali nedeniyle hasta takibe alınmalıdır. Grafilerin yetersiz kaldığı hastalarda BT ve MR görüntülemelerinden yararlanılabilir. Tip 3 kırıklar artroskopik veya açık teknik ile tedavi edilebilir. Transosseöz sütürler ve kanüle vida, tespit amacıyla kullanılabilir. Operasyonda menisküsler kontrol edilmelidir. İntermeniskal bağ ve mediyal menisküs ortaya konmalı ve osteokondral parçanın altında kaldıysa ayrılmalıdır. Erken çocukluk döneminde kırık parça genellikle geniştir ve tespiti genellikle stabiliteyi sağlar. Ancak adolesan dönemde kemik parça daha küçüktür ve ön çapraz bağın distal yüzüne de tespit gerekebilir. Transfiziyel vidalar, olgunlaşmamış iskelette epifizyodez etkisi oluşmaması için ortalama 3-6 ay sonra çıkarılmalıdır. Tamirden sonra, diz ekstansiyondayken alçılama yapılıp, redüksiyonun devamlılı̆ı açısından hasta yakın takibe alınmalıdır. Takiplerde, bu hastalarda artrofibrozis görülebildiğinden, eğer mümkünse fizik tedavi ilk dört haftanın sonunda başlatılmalıdır. Tedavi sonrası hastalar, genellikle yaralanma öncesindeki aktivitelerine dönebilirler; ancak bazı hastalarda ön çapraz bağ gevşekliği oluşabilmektedir. Bu hastalarda translasyonel ve rotasyonel hareketlerle instabilite sık görülür.

\section{Proksimal Tibia Metafiz Kırıkları}

Bu bölge kırıkları 3-6 yaş arasındaki çocuklarda daha sık görülür ve genellikle diz ekstansiyondayken mediyal bölgeye torsiyonel kurvetlerin etkisiyle ya da lateral bölgeye alınan direkt travmayla oluşur. Genellikle, ayrışmamış, mediyal korteksin kırıldığı, lateral korteksin sağlam kaldığı yeşil ağaç kırıklarına rastlanır. Fibular kırık genellikle eşlik eden patoloji olmamakla birlikte, fibulanın plastik deformasyonu görülebilir. Ancak, yüksek enerjili travmalarda fibula kırığı izlenebilmektedir. Nörovasküler yaralanmanın eşlik etmesi fazla beklenmemekle beraber, peroneal sinir mutlaka kontrol edilmelidir. ${ }^{[2,6-9]}$

Tibia proksimal metafiz kırığı bulunan hastalar, etkilenen bölgede ağrı şikâyetiyle başvururlar. Minimal yumuşak doku şş̧liği izlenebilir. Ön-arka ve yan grafilerde kırık tespit edilebilir. Genellikle konservatif tedavi yeterlidir. Valgus deformitesi meydana gelen hastalarda sedasyon altında kapalı redüksiyon uygulanabilir. Uzun bacak alçılama yapıldıktan sonra redüksiyonun devamlılığının sağlanması açısından iki hafta sonra grafi ile kontrolünün yapılması uygun olacaktır. Alçı tedavisi 4-6 hafta kadar uygulanır. Alçı çıkarıldıktan sonra, takiplerde alt ekstremitede gelişebilecek valgus deformitesi (Cozen fenomeni) açısından hastanın ailesi uyarılmalıdır (Şekil 3). Tedavi 
sonrası en sık görülen komplikasyonlardan olan bu deformitenin gelişme riski 12.-18. aylarda daha yüksektir ve bazı durumlarda $20^{\circ}$ 'ye kadar açılanma görülebilir. Başlangıç tedavisinde tam redüksiyonun sağlanamaması, erken yük verme, iliotibial bant gerginliği ve yumuşak doku interpozisyonunun bu deformiteye neden olabileceği bildirilmektedir. Hastaların büyük çoğunluğunda deformite en geç üç yıl içinde kendiliğinden düzelir. Illk bir yıl içinde düzelme eğilimine girmeyen deformiteler daha sıkı takip edilmelidir. Açılanması $15-20^{\circ}$ 'den fazla olan veya üç yıl geçmesine rağmen düzelme gerçekleşmeyen olgularda, akut veya tedrici düzeltici cerrahiler gerekebilmektedir. Başlangıçtan itibaren uygun dizilimin sağlanamadığı veya kapalı redüksiyonun başarılı olmadığı olgularda erken cerrahi tedavi tercih edilebilir. ${ }^{[1,3,6]}$

\section{Proksimal Tibial Fizis Kırıkları}

Proksimal tibial fizis kırıkları seyrek rastlanan yaralanmalardır. Çocukluk çağı fizis kırıklarının \%0,53'ünü kapsar. Bu yaralanmaların seyrek olmasında kollateral bağların bu bölgeye tutunmamasının rol oynadığı düşünülmektedir. Bu bağlar, femur distalinden fibula proksimali ve tibia metafizine tutunarak valgus ve varus kuvvetlerini daha distale iletir.

Dizin doğrudan ve dolaylı travmaları proksimal tibial fizis kırıklarına neden olabilir. Alt ekstremite sabitken hiperekstansiyondaki dize indirekt travma, daha sık görülen mekanizmadır. Hastaların önemli bir kısmı 13-16 yaşlarındaki erkek çocuklardır. On altı yaşından büyük çocuklarda, anterior tibial proksimal fizis açıktır, posterior tibial proksimal fizis ise kapanmaya başlamıştır. Hastaların \%42'sinden fazlasında, başta fibula kırıkları olmak üzere tibia ve femur şaft kırıkları, kollateral bağ yaralanması, patella kırıkları, kuadriseps kası yırtığı eşlik edebilir. Nörovasküler yapıların yakın komşuluğu nedeniyle muayene dikkatli yapılmalıdır. ${ }^{[5-8]}$

Proksimal tibial fizis kırıklarında Salter-Harris sınıflaması kullanılır. Tip 1 kırıklar, grubun \%15'ini oluşturur ve bunlar genellikle ayrışmamıştır. Kırık hattı büyüme plağına uzanır, epifiz ve metafiz ayrılmıştır. [4] Tedavide alçı ile takip yapılmalıdır. Tip 2 kırıklar en sık görülen (\%37) tiptir. Sıklıkla mediyal fizis hasarı ve lateral metafiziyel parçanın oluştuğu valgus stresi ile oluşur. Kırıkların çoğu mediyale doğru ayrışmıştır. Pes anserinus ve periost gibi çevre dokuların araya girmesi nedeniyle, kapalı redüksiyon başarısız olabilir. ${ }^{[5]}$ Tip 3 kırıklar daha nadirdir (\%21). Ön-arka grafide tibia kondillerinde, yan grafide tibial tüberkül veya tibia epifiz anteriorunda gözlenebilir. Bu kırıklar genellikle ayrışmıştır ve cerrahi tedavi gerekebilir. Tip 4 kırıklar nadirdir; dolaylı travmaya maruz kalan hastalarda lateral tibial platoda görülür ve cerrahi tedavi gerektirir. Tip 5 kırıklar da nadirdir ve tanısı genellikle geriye dönük olarak konulur. ${ }^{[7-9]}$

Proksimal tibial fizis kırıklarında, etkilenen dizde şişlik vardır ve eklem fleksiyondadır. Diz ekstansiyonu ağrılıdır ve hamstring spazmı eşlik eder. Direkt lateral bölge travmalarında valgus deformitesi oluşabilir. Nörovasküler değerlendirme için distal nabızlar palpe edilmelidir. Distal nabızların palpe edilemediği deplase kırıklarda, hızla redüksiyon sağlanmalı ve ardından tekrar muayene yapılmalıdır. Şüpheli durumlarda arteriyografi endikasyonu mevcuttur. Kompartman sendromu açısından hasta yakın takip edilmelidir.

Tedavide amaç redüksiyon, redüksiyonun devamlılığının sağlanması ve fizis yaralanmasını önlemektir. Redüksiyon sedasyon altında denenmelidir. Ayrışmamış kırıklarda konservatif tedavi tercih edilir. Ayrışmış kırıklarda anestezi altında redüksiyon denenip 4-6 hafta alçı tedavisi uygulanır. Alçılamanın ardından dolaşım takibine devam edilmeli, gerektiğinde alçı bivalve edilmelidir. Kapalı redüksiyonun başarısızlığı, idame ettirilememesi, Salter-Harris Tip 3 ve 4 kırıklar, arter hasarı ve aynı tarafta başka bir kırık varlığı, cerrahi tedavi endikasyonlarıdır. Tedavide K-telleri ve epifizde yeterli genişlik bulunan olgularda fizise paralel olarak konulan vidalar kullanılabilir. ${ }^{[3,6]}$

Proksimal tibial fizis kırıkları sonrası büyüme kıkırdağı hasarı, açısal deformite ve bacak uzunluk eşitsizliği gelişme riski \%10-15 oranında bildirilmiştir. Eşlik eden bağ yaralanmaları \%60 oranında görülmektedir. Başlangıç muayenesinde diz instabilitesini değerlendirmek zordur. Stabilizasyon sağlandıktan sonra veya kırık iyileşmesinin ardından bağlar değerlendirilmelidir. ${ }^{[4-6]}$

\section{TiBiA DIYAFIZ KIRIKLARI}

\section{Epidemiyoloji}

Tibia ve fibula kırıkları, önkol ve femur kırıklarından sonra çocuklarda görülen en sık üçüncü uzun kemik kırıklarıdır. ${ }^{[7-9]}$ Tüm tibia kırıklarının \%50-70'i distal tibiayı, \%19-39'u tibia diyafiz 1/3'ünü kapsar. Kırık oluş mekanizması, 1-4 yaş arasında düşme ve bisiklet kazaları; 4-14 yaş arasında ise spor yaralanmaları veya trafik kazalarıdır. Bu kırıkların yaklaşık \%9'u açık kırıktır. ${ }^{[8]}$

Kruris kırıklarının \%70'inde sadece tibia kırığı görülür. ${ }^{[8]}$ Bunlar torus, yaş ağaç ve tam kırık olabilir. En sık 11 yaş altında, torsiyonel güce maruz kalmış ve $1 / 3$ tibia distalini oluşturan kırık olarak karşımıza çıkar. Önemli bir kısmı oblik ve spiral kırık olup, ayak sabit bir pozisyondayken vücudun rotasyonel hareketi ile 


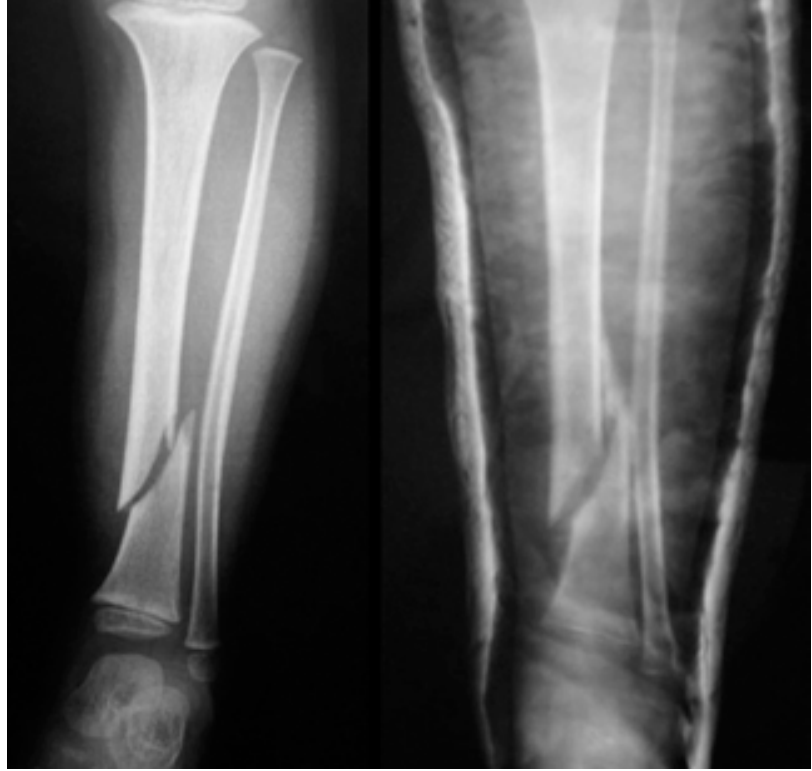

Şekil 4. İzole tibia distal diyafiz kırığı olan hastada alçı tedavisi sırasında gelişen varus deformitesi.

oluşur. Kırık hattı radyografide, genellikle distalde anteromediyalden başlayıp proksimalde posterolaterale ilerler. Fibula kırığının olmaması, tibiada kısalma oluşmasını önler; ancak takiplerde hastaların \%60'ında varus açılanması oluşur. ${ }^{[10]}$ Bunun nedeni, fibulanın intakt olması dolayısıyla fleksör kasların krurisi varusa getirmesidir (Şekil 4). İzole tranvers ve parçalı kırıklar ise sıklıkla doğrudan travma ile oluşur.

Pediatrik tibia diyafız kırıklarının \%30'una fibula kırığı da eşlik eder. Tibia ve fibula diyafiz çift kırıklarında, genellikle kruriste valgus deformitesi görülür. İzole fibula diyafız kırıkları ise çocuklarda nadiren gözlenir ve immobilizasyon ile hızlıca iyileşir. ${ }^{[10]}$

\section{Belirti ve Bulgular}

Kırık oluşum mekanizmasına göre, klinik yansımalar değişkenlik gösterir. Ağrı, kırık çevresinde şişlik ve hassasiyet vardır. Hastalar ilgili ekstremiteye yük veremezler. Ayrışmış kırıklarda deformite gözlenebilir. Nörolojik hasar nadirdir. Arteriyel yaralanma, kruris diyafız kırıklarında nadiren görülmesine rağmen, muayenede dorsalis pedis ve posterior tibial arter nabızları palpe edilmeli ve kapiler dolum kontrol edilmelidir. Radyolojide, tibia ve/veya fibula diyafiz kırı̆ından şüpheleniliyorsa, diz ve ayak bileğini içeren ön-arka ve yan grafiler çekilmelidir. Yaygın olmamakla beraber, tibia diyafız kırıklarına ek olarak distal tibia metafizini içeren kırıklar da görülebilmektedir. ${ }^{[8]}$
Tablo 1. Pediatrik tibia diyafiz kırıkları için kabul edilebilir dizilim sınırları

\begin{tabular}{lll}
\hline Deformite & $<8$ yaş & $>8$ yaş \\
\hline Valgus & $10^{\circ}$ & $5^{\circ}$ \\
Varus & $10^{\circ}$ & $5^{\circ}$ \\
Sagittal planda açılanma & $10^{\circ}$ & $5^{\circ}$ \\
Kısalık & $15 \mathrm{~mm}$ & $10 \mathrm{~mm}$ \\
Rotasyon & $5^{\circ}$ & $5^{\circ}$ \\
Translasyon & $\% 50$ & $\% 50$
\end{tabular}

\section{Tedavi}

Pediatrik tibia ve fibula kırıklarının büyük çoğunluğu konservatif yöntemlerle tedavi edilebilir. Konservatif tedavi için kabul edilebilir açılanmalar yaşa göre değişkenlik gösterir (Tablo 1). ${ }^{[8,11,12]}$ Konservatif tedavide proksimal femura kadar uzanan ve dizin $20-45^{\circ}$ fleksiyonda olduğu uzun bacak alçı yapılır. Kırık hattının posteriora açılanmasını (rekurvatum deformitesini) önlemek için ayak bileği; orta ve distal $1 / 3$ kruris kırıkları için $20^{\circ}$, proksimal $1 / 3$ kruris kırıklarında ise $10^{\circ}$ plantar fleksiyonda tutulmalıdır. Çocuklarda, alçı sonrasında takiplerde kalıcı ekinus kontraktürü nadiren görülür. Tedavi süresi 4-6 hafta kadardır. Üçüncü haftada alçı diz altına kadar kısaltılabilir. Konservatif tedavi seçilen hastalarda, zamanla oluşan kas atrofisi ve yumuşak doku ödeminin azalması sonrası alçıda bollaşma, kırık hattında ayrışmaya neden olabilmektedir. Bu nedenle ilk haftalar yakın takip yapılmalıdır. ${ }^{[8-12]}$

Pediatrik tibia diyafiz kırıklarının tedavisinde son zamanlarda cerrahi yöntemler daha sık tercih edilmeye başlamıştır. Cerrahi tedavi; açık kırıklarda, kompartman sendromu içeren durumlarda, yüzen diz, çoklu kemik kırıkları ve çoklu organ yaralanması olan hastalarda, konservatif tedavi ile uygun dizilimin elde edilemeyeceği veya korunamadığı kırıklarda tercih edilir. Tespit amacıyla K-telleri, esnek intramedüler çiviler, plak-vida ve eksternal fiksatörler kullanılabilir. En sık görülen komplikasyon gecikmiş kaynama olup, bazı çalışmalarda \%18'lere kadar çıkmaktadır. Yaş arttıkça bu oran daha da artar. ${ }^{[13-15]}$

\section{Açık Tibia Kırıkları}

Açık tibia kırıklarının tedavisi, erişkinlerdeki gibidir. Sınıflandırmada Gustillo-Anderson sınıflaması kullanılır. Vasküler hasar açık tibia kırıklarının \%5'inde belirlenmiştir. Ampütasyonlar tip 3C olgularda \%79'lara 
kadar çıkmaktadır. İzole anterior tibial ve peroneal arter yaralanmalarının prognozu daha iyiyken; posterior tibial ve popliteal arter yaralanmalarının prognozu ve vasküler tamir/rekonstrüksiyona cevabı daha kötüdür. ${ }^{[6,12,15]}$

\section{Tedavi prensipleri}

- En kısa sürede debridman ve yıkama yapılmalı.

- Tetanoz ve antibiyotik profilaksileri yapılmalı.

- Kırığın internal veya eksternal tespiti yapılmalı.

- Perfüzyonda yetmezlikten şüphelenilmesi durumunda ameliyat esnasında müdahale (cerrahi veya anjiyografik) edilmeli.

- Çevre yumuşak doku olabildiğince kapatılmalı.

- Nekrotik yumuşak doku veya kemik varlığında, kapamaya elverişli hale gelecek şekilde seri debridmanlar yapılmalı.

\section{Çocuklardaki açık tibia kırıklarının erişkinlerden farklılıkları}

- Yumuşak doku örtümü ve kemik iyileşmesi özellikle küçük çocuklarda daha iyidir.

- Nonvital ancak kontamine olmayan kemik parçaları için yumuşak doku örtümü planlanabilir. Bu yapılar daha sonrasında otogreft özelliği göstererek kaynamaya katkıda bulunabilir.

- Periostunun korunması durumunda, segmental kayıp olsa bile kemik yapı kendini şekillendirebilir.

\section{Distal Tibia Metafiz Kırıkları}

Bunlar sıklıkla, kompresif güçler nedeniyle oluşan yaş ağaç kırıkları olarak karşımıza çıkar. Anterior kortekste impaksiyon gözlenirken, posterior kortekste periostun yırtılmasına bağlı ayrışma görülebilir. Bu nedenle, sıklıkla rekurvatum deformitesi ile karşılaşırız. Ayak bileğinin plantar fleksiyonda olduğu, uzun bacak alçı ile tedavi edilir. Üç hafta sonra kısa bacak alçıya geçilebilir. Tedavi süresi hastanın yaşına bağlı olarak 4-6 hafta civarındadır. Stabil olmayan kırıklarda antegrad esnek çiviler, kapalı redüksiyon K-teli ile tespit veya açık redüksiyon/plak-vida veya sadece vida ile tespit uygulanabilir. ${ }^{[12,15]}$

\section{Toddler Kırı̆̆ı}

Diz fleksiyonda ve ayak dış rotasyondayken tibianın maruz kaldığı travmaya bağlı meydana gelen ve fibula kırığının eşlik etmediği spiral kırıklara Toddler kırığı denilmektedir. ilk olarak 1964'te tanımlanmıştır. Ortalama görülme yaşı 27 aydır. Toddler kırığını tanımlayan Dunbar'a göre kırık erkeklerde ve sağ tarafta daha çok görülür. ${ }^{[16]}$ Tanının konulması için çekilen ön-arka ve yan grafilerde kırık hattı her zaman görülemeyebilir. Şüpheli olgularda ek olarak iç rotasyonda oblik grafi çekilmelidir. Üç ila dört haftalık uzun bacak alçı tedavisi yeterlidir. İkinci haftadan sonra kısa bacak alçıya geçilebilir.

\section{KAYNAKLAR}

1. Tileston K, Frick S. Proximal Tibial Fractures in the Pediatric Population. J Knee Surg 2018;31(6):498-503. Crossref

2. Mubarak SJ, Kim JR, Edmonds EW, Pring ME, Bastrom TP. Classification of proximal tibial fractures in children. J Child Orthop 2009;3(3):191-7. Crossref

3. Shin YW, Uppstrom TJ, Haskel JD, Green DW. The tibial eminence fracture in skeletally immature patients. Curr Opin Pediatr 2015;27(1):50-7. Crossref

4. Cepela DJ, Tartaglione JP, Dooley TP, Patel PN. Classifications In Brief: Salter-Harris Classification of Pediatric Physeal Fractures. Clin Orthop Relat Res 2016;474(11):2531-7. Crossref

5. Whan A, Breidahl W, Janes G. MRI of Trapped Periosteum in a Proximal Tibial Physeal Injury of a Pediatric Patient. Am J Roentgenol 2003;181(5):1397-9. Crossref

6. Kay RM. Pediatric Pelvic and Lower Extremity Fractures and Child Abuse. In: Liebermann JR, editor. AAOS Comprehensive Orthopaedic Review, Volume 1. Rosemont: American Academy of Orthopaedic Surgeons; 2009. pp.233-45.

7. Cheng JCY, Shen WY. Limb fracture pattern in different pediatric age groups: a study of 3,350 children. J Orthop Trauma 1993;7(1):15-22. Crossref

8. Mooney JF 3rd, Hennrikus WL. Fractures of the Shaft of the Tibia and Fibula. In: Flynn JM, Skaggs DL, Waters PM, editors. Rockwood and Wilkins' Fractures in Children, 8th ed. Philadelphia: Lippincott Williams \& Wilkins; 2004. pp.1137-69.

9. Mashru RP, Herman MJ, Pizzutillo PD. Tibial shaft fractures in children and adolescents. J Am Acad Orthop Surg 2005;13(5):345-52. Crossref

10. Yang JP, Letts RM. Isolated fractures of the tibia with intact fibula in children: a review of 95 patients. J Pediatr Orthop 1997;17(3):347-51. Crossref

11. Dwyer AJ, John B, Krishen M, Hora R. Remodeling of tibial fractures in children younger than 12 years. Orthopedics 2007;30(5):393-6.

12. Gordon JE, O'Donnell JC. Tibia fractures: What should be fixed? J Pediatr Orthop 2012;32 Suppl 1:S52-61. Crossref

13. Bartlett CS 3rd, Weiner LS Yang EC. Treatment of type II and type III open tibia fractures in children. J Orthop Trauma 1997;11(5):357-62. Crossref

14. Malhotra K, Pai S, Radcliffe G. Do minimally displaced, closed tibial fractures in children need monitoring for compartment syndrome? Injury 2015;46(2):254-8. Crossref

15. Setter KJ, Palomino KE. Pediatric tibia fractures: Current concepts. Curr Opin Pediatr 2006;18(1):30-5.

16. Dunbar JS, Owen HF, Nogrady MB, McLeese R. Obscure Tibial Fracture of infants -The Toddler's Fracture. J Can Assoc Radiol 1964;15:136-44. 